\title{
O DIREITO DO TRABALHO POR EVARISTO DE MORAES FILHO: UMA CONTRIBUIÇÃO À COMPREENSÃO DA CULTURA JURÍDICA TRABALHISTA BRASILEIRA.
}

\section{THE LABOUR LAW BY EVARISTO DE MORAES FILHO: A CONTRIBUTION TO UNDERSTANDING OF BRAZILIAN LABOR LAW CULTURE.}

\section{Sayonara Grillo Coutinho Leonardo da Silva ${ }^{1}$}

Resumo: O objetivo do artigo é examinar as concepções de Direito do Trabalho presentes na obra de Evaristo de Moraes Filho, em especial o debate sobre as funções e sentidos deste ramo. Para tanto, apresenta o autor, com sua múltipla formação e dupla inserção - acadêmica e profissional - nas áreas de ciências jurídicas e sociais, e se referencia em estudos que o situam no âmbito do pensamento social brasileiro e da repercussão de sua obra na sociologia do trabalho e no direito coletivo. A partir das teses que o descrevem como um pensador não canônico nas ciências sociais, indaga se, no campo laboral, os referenciais analíticos presentes em sua obra jurídica denotam um caráter não hegemônico de suas concepções teóricas. Realiza tal percurso com uma revisão bibliográfica de e sobre Moraes Filho. Argumenta que a recursa à tese da outorga e do insolidarismo se faz acompanhada da afirmação de um caráter compromissório e de mediação do direito laboral. Conclui, destacando a singularidade metodológica do jurista. Encerra com um inventário de temas de pesquisa que permitem ampliar a compreensão sobre a contribuição de Evaristo de Moraes Filho para a cultura jurídica trabalhista.

Palavras-chave: DIREITO DO TRABALHO. CULTURA JURÍDICA. EVARISTO DE MORAES FILHO.

Abstract: This paper's objective is to examine the conceptions of Labor Law found in Evaristo de Moraes Filho's work, especially the debate on the functions and meanings of this field. It presents the author, with his multiple trainning and double insertion - academically and professionally - in the legal and social sciences' fields, and is based on studies that locate

\footnotetext{
${ }^{1}$ Doutora em Ciências Jurídicas pela Pontifícia Universidade Católica do Rio de Janeiro.

Professora Adjunta da Faculdade Nacional de Direito da Universidade Federal do Rio de Janeiro, Rio de Janeiro, Brasil.
} 
him within the Brazilian social thought and the impact of his work in the Labor and collective rights' sociology. It asks, based on thesis that describe him as a non-canonical thinker in social sciences, whether, in the labor field, the analytical references present in his legal work denote a non-hegemonic character of his theoretical conceptions. It performs such route with a literature review by and on Moraes Filho. It argues that the recursion to the thesis of the grant and the lack of solidarity is done accompanied by the statement of an undertaking and mediating character of labor law. It concludes highlighting the jurist's methodological uniqueness. Concluding with an inventory of research themes to broaden the understanding of Evaristo de Moraes Filho's contribution for labor legal culture.

Keywords: LABOR LAW. JUDICIAL CULTURE. EVARISTO DE MORAES FILHO.

\section{INTRODUÇÃO}

Ao indagar sobre as razões de ser do Direito do Trabalho, em seu já clássico Direito do Trabalho e Ideologia, Manuel-Carlos Palomeque-Lopez observa que sua funcionalidade como disciplina jurídica independente reside na canalização ou institucionalização do conflito entre o capital e o trabalho assalariado sendo, pois, uma categoria cultural fruto do sistema capitalista industrial. ${ }^{2}$ À noção de categoria cultural se acresce a compreensão da profunda historicidade do direito laboral, de seu caráter ambivalente ou contraditório, que desempenha o papel de juridificação do conflito mediante conteúdos diversos, com variações autoritárias e democráticas.

A combinação de elementos em disputa e a dinâmica constitutiva na formulação de distintos desenhos sugerem a inexistência de uma modelagem prévia do sistema jurídico laboral, ao menos como forma de representação abstrata ou conceitual. Tal tensão perpassa de tal modo as narrativas das configurações dos modelos de Direito do Trabalho que uma aproximação crítica dos processos constituintes, ao lado da articulação entre modos de regulação e da cultura jurídica, a partir de uma noção compreensiva, apresenta-se como

\footnotetext{
2 “O Direito do Trabalho é, desde logo, uma categoria cultural fruto do sistema capitalista industrial. Não é, portanto, a resposta normativa ao conflito sociolaboral ou de trabalho em geral, na medida em que todas as sociedades históricas conheceram o trabalho como fonte de conflitos sociais sem que, por isso, possa registrar no seu seio o nascimento daquele sistema normativo, mas propriamente a reacção ante o conflito industrial, o conflito entre o capital e o trabalho assalariado na sociedade capitalista industrial, o conflito que se gera na 'grande indústria' do séc. XIX, caracterizada por uma dupla concentração de capitais e de trabalhadores. Não é, pois, mais um conflito, dentro de uma estrutura social pluralmente conflituosa, como é a sociedade capitalista, mas, antes, de um autêntico motor de todas as suas contradições, do seu conflito central ou paradigmático.” (PALOMEQUE, 2001, p.17).
} 
substancialmente adequada para captar os fundamentos de políticas legislativas concretas (BAYLOS GRAU, 2014). ${ }^{3}$

Entre nós, este tipo de reflexão é pouco comum. Poucas são as pesquisas que indagam sobre as contribuições de nossos juristas para a formação do Direito do Trabalho. ${ }^{4}$ A esta escassez se soma certa tendência a um reverencialismo que permeia a assimilação da doutrina na área, com citações apresentadas com transcrições que se sucedem sem diálogo para abrilhantar, com pretensa erudição, os argumentos de autoridade que sustentam a lógica advocatícia da construção dogmática de manuais ${ }^{5}$. Sabe-se que tal lacuna vem diminuindo, com um conjunto de investigações que advém da história do direito e da historiografia ou sociologia do trabalho. ${ }^{6}$ Contudo, um mapeamento das narrativas, das discussões entre os doutrinadores e de seus aportes para as opções e interpretações que o Direito do Trabalho assumiu ao longo de seu primeiro século de existência no país persiste como tarefa por realizar. Afinal, o papel dos juslaboralistas importa. Suas trajetórias e seus aportes para a configuração do Direito do Trabalho merecem ser estudadas.

Evaristo de Moraes Filho é um caso à parte. Há sólida produção ${ }^{7}$ sobre o arquiteto da sociologia e do direito do trabalho no Brasil (MOREL; GOMES; PESSANHA, 2007), sua contribuição à sociologia do direito e sua leitura sobre o problema do insolidarismo. ${ }^{8}$ Estudos

\footnotetext{
${ }^{3}$ A respeito da relação entre modelos de Direito do Trabalho e cultura jurídica, ver Baylos Grau, que parte de uma noção ampliada de cultura jurídica como "conjunto de enfoques, conglomerado de teorias e doutrinas jurídicas elaboradas por juristas em uma determinada fase histórica, como ideologias, modelos de justiça e modos de pensar sobre o direito próprios dos operados jurídicos profissionais, juízes, assessores etc.” (BAYLOS GRAU, 2014, p.19)

${ }^{4}$ Registrem-se, como exceções, expressivos estudos sobre o pensamento de Oliveira Vianna para a formação do direito coletivo do trabalho no Brasil, a reconstrução do debate da década de 1930-1940 entre o sociólogo e jurista ideólogo do direito corporativo no Brasil e o jurista Waldemar Ferreira, bem como o substancial conjunto de estudos sociológicos sobre pensamento social brasileiro.

${ }^{5}$ Luciano Oliveira faz um interessante inventário de problemas usuais na pesquisa jurídica, tais como o manualismo e o reverencialismo, que relaciona com a utilização indevida e "ostensivamente anticientífica" do chamado argumento de autoridade. Assim, a apropriação dos autores passa por um processo de naturalização e de despolitização, com a construção de verdadeiros sensos comuns teóricos, amparados por falas de autoridade, sem contextualização, reflexão e análise.

${ }^{6}$ Sem pretender fazer um levantamento exaustivo, registro as entrevistas realizadas por Ângela Castro Gomes, Elina Pessanha e Regina Morel, organizadoras de Sem Medo da Utopia (2007) e Um Construtor do Direito do Trabalho (2004), respectivamente, com atores relevantes para a cultura jurídica trabalhista brasileira, como Evaristo de Moraes Filho e Arnaldo Sussekind, bem como pelas duas primeiras autoras, o Trajetórias de Juízes (2010). A historiadora Ângela de Castro Gomes organizou recentemente com Fernando Teixeira, livro com produção consistente a partir de fontes diretas produzidas pelo judiciário, A Justiça do Trabalho e sua história (2013).

${ }^{7}$ Defendidas no Programa de Sociologia e Antropologia da Universidade Federal do Rio de Janeiro, registro as dissertações de Antonio da Silveira Brasil Júnior (Uma sociologia brasileira da ação coletiva: Oliveira Vianna e Evaristo de Moraes Filho) e Jefferson Almeida Silva (A sociologia do direito como mecanismo de mudança social no Brasil), além dos estudos de Glaucia Villas Bôas, Elina Pessanha, José Murilo de Carvalho, José Sérgio Leite Lopes, Regina Morel, Wander Bastos etc.

8 “Insolidarismo social é a expressão que define a 'falta' ou a 'ausência’ de instituições organizadas livremente para atender a interesses de grupos, e cuja durabilidade é essencial para que sejam reconhecidas e se tornem eficazes. A fugacidade das instituições no Brasil, como uma característica da cultura brasileira, tornara-se questão relevante no pensamento de Oliveira Vianna, mas, segundo Evaristo, dela tinham se ocupado também Gilberto Freyre, Capistrano de Abreu, Sérgio Buarque de Holanda, Alberto Torres e Tobias Barreto (MORAES FILHO, 1978, p. 314-319). O insolidarismo devia ser combatido programaticamente, evitando-se a fragmentação e o afrouxamento dos laços de instituições e associações. Diferenciando-se, porém, de seus interlocutores, Evaristo escreve um livro em que as associações operárias e sindicais adquirem centralidade na pesquisa e reflexão do autor, levando-o a argumentar que a pressão política que exerceram, em finais do século XIX e
} 
se debruçaram sobre seu papel como "valorizador obstinado da contribuição das lutas sociais populares", de "avanços como um balizador e formulador de princípios mais democráticos para as relações de trabalho no Brasil” (PESSANHA, 2005, p. 14). A vastidão da obra, a excelência das reflexões, a pluralidade de interesses e de campos de estudo, o rigor como investigador, o pioneirismo na arena universitária, a perseguição política, a prisão e o expurgo sofrido, o labor como procurador do trabalho, a atuação propositiva legislativa, o reconhecimento literário, são apenas alguns dos aspectos destacados quando se apresenta a obra e a vida do catedrático de Direito do Trabalho da Faculdade Nacional de Direito, atualmente professor emérito da Universidade Federal do Rio de Janeiro (UFRJ) e integrante da Associação Brasileira de Letras (ABL).

O presente ensaio realiza um inventário das concepções sobre o Direito do Trabalho, seus fundamentos, objetivos e funções, pelo estudo da doutrina produzida por Evaristo ao longo de três décadas de consolidação e autonomização do ramo juslaboral no Brasil. Para tanto, traz elementos biográficos e se referencia em obras que avaliam sua importância para o pensamento social brasileiro. Apresenta o pioneirismo de suas abordagens no campo da historiografia do trabalho e das ciências sociais. Realiza tal percurso com uma revisão bibliográfica de e sobre Moraes Filho. ${ }^{9}$ Almeja-se explicitar aspectos que permitem situá-lo em posição singular na cultura trabalhista brasileira, diante da perspectiva metodológica interdisciplinar, em um viés comprometido com a democracia, de um socialista possibilista. ${ }^{10}$

\section{UMA APRESENTAÇÃO}

O jurista e sociólogo Evaristo de Moraes Filho nasceu em julho de 1914, no Rio de Janeiro, onde ainda reside. Filho de Evaristo de Moraes, o Tribuno da República (MENDONÇA, 2007) e primeiro consultor jurídico do Ministério do Trabalho, Indústria e Comércio, ${ }^{11}$ Evaristo de Moraes Filho foi alcunhado de produto e produtor da universidade,

\footnotetext{
primeiras décadas do século XX, foi indispensável para a formulação das leis trabalhistas no país.” (VILLAS BÔAS, 2004, p. 20).

${ }^{9}$ Estudos pioneiros e que examinaram com percuciência a relação de Evaristo com o Direito do Trabalho foram produzidos pelos professores Antonio Carlos Flores de Moraes (Evaristo e o Direito do Trabalho) com reflexões sobre Evaristo como doutrinador, como legislador, e sobre seu destemor, e pela professora Elina Pessanha (Evaristo de Moraes Filho: fundamentos democráticos dos direitos do trabalho no Brasil). (PESSANHA, VILLAS BOAS, MOREL, 2005).

${ }^{10}$ Conforme sugere e descreve Elina Gonçalves da Fonte Pessanha, precursora do estudo da influência de Evaristo no Direito do Trabalho no Brasil. Segundo a autora, "o socialismo possibilista, de olho das possibilidades", é um termo cunhado pelo autor para referir-se a socialistas que o precederam (2007, p. 160).

${ }^{11}$ Sobre a vida e obra de Evaristo de Moraes, consultar Joseli Mendonça (2007). Evaristo de Moraes (o pai) atuou em defesa dos trabalhadores, de sindicatos, contra a repressão às greves. Escreveu Apontamentos de Direito Operário, em 1905, reunindo artigos publicados em jornais diversos e integrou a consultoria jurídica do Ministério do Trabalho introduzido pela Revolução de 1930. (MENDONÇA, 2007).
} 
pela socióloga Regina Morel, sua filha e também professora da Universidade Federal do Rio de Janeiro, tal como o pai e o avô o foram (MOREL, 2015). Entre seu primeiro vestibular aos 18 anos até a aposentadoria compulsória aos 55 anos, vivenciou intensamente a ambiência acadêmica nas Faculdades de Direito, de Filosofia e no Instituto de Ciências Sociais. Seja como estudante, desde 1933, ou como professor (1950 a 1969), Evaristo atuou nos momentos de formação e desenvolvimento do ensino do Direito do Trabalho no Brasil até sua prisão e aposentadoria compulsória após o AI-5. ${ }^{12}$

Na Faculdade Nacional de Direito, onde se formou na conhecida turma de 1937, ${ }^{13}$ Evaristo participou de uma arena de forte polarização ideológica, com grupos integralistas, socialistas, anarquistas, comunistas e católicos, atuando fortemente entre os estudantes. Durante sua graduação, em 1935, três influentes professores progressistas - Leônidas Resende, Hermes Lima e Castro Rebelo - foram presos, afastados pelo regime autoritário após o fechamento da Aliança Nacional Libertadora (ANL) e só retornariam às cátedras em 1945. Tais docentes tiveram significativa influência na formação de Evaristo Moraes Filho, ${ }^{14}$ que fundara com Délio Maranhão e Dante Viggiani, a Ideia, revista estudantil de conteúdo político “de esquerda socialista, de reforma social."15 Ainda estudante, trabalhou como secretário das Comissões Mistas de Conciliação, do Ministério do Trabalho, Indústria e Comércio (1934-1940), que mediavam conflitos coletivos e greves. ${ }^{16}$

\footnotetext{
12 Sobre a trajetória de Evaristo de Moraes Filho na Universidade, consultar a Biblioteca Virtual Evaristo de Moraes Filho. Disponível em: < http://www.bvemf.ifcs.ufrj.br/>. Acesso em 10 de outubro de 2015 e MOREL 2015. Em 1939, ingressa na primeira turma da Faculdade de Filosofia, curso interrompido e concluído no interregno de 1946 a 1949. Por um ano, entre 1941 e fevereiro de 1942, atuou na instalação da Justiça do Trabalho no estado da Bahia. Nos anos 1950, defendeu três teses em concursos de Livre-Docência e para a Cátedra. O professor Evaristo de Moraes Filho será detido e mantido incomunicável por uma semana pelo regime militar, antes de ser aposentado compulsoriamente. Após recusar a anistia, Evaristo foi agraciado com o título de professor emérito da UFRJ em 1983.

${ }^{13}$ Trata-se da primeira turma formada após a reunião das Faculdades e criação da Universidade do Brasil, na qual, além de Evaristo de Moraes Filho, se sobressaiu Délio Maranhão. Segundo Moraes Filho: “a turma de 1937 foi a melhor que já passou pela Faculdade de Direito, e a mais numerosa. Dela saíram três ministros do Supremo Tribunal Federal, quatro ou cinco catedráticos em diversas universidades, seis ou sete embaixadores, além de escritores" (MOREL; GOMES; PESSANHA, 2007, p. 35).

${ }^{14}$ Evaristo de Moraes Filho. Entrevista. Apud: CACO: 90 anos de história. Coordenadoria de Comunicação da Universidade Federal do Rio de Janeiro. Rio de Janeiro: UFRJ, 2007. Disponível em: < http://www.ufrj.br/sgcoms/docs/MemorabiliaCACO-90-ANOS-de-HISTORIA.pdf.>, p. 33 e Alberto Venâncio Filho (2005, p. 22). Para Venâncio Filho, entretanto, a maior fonte de inspiração de Evaristo Filho foi seu pai Evaristo de Moraes, advogado destacado na defesa de sindicalistas, autor de Apontamentos de Direito Operário (1905) e primeiro consultor jurídico do Ministério do Trabalho, da Indústria e do Comércio, entre 1930 e 1932.

15 Trechos extraídos de entrevista concedida aos alunos do Centro Acadêmico Candido de Oliveira (CACO) para o livro sobre a história do CACO em seus 90 anos, o qual contém entrevistas com personagens que partilharam da trajetória daquele órgão estudantil. No ambiente polarizado da Nacional, Evaristo se posicionava: “eu era de esquerda”. À época, Evaristo não se filiara à ANL por ser funcionário das Comissões Mistas de Conciliação. No período pós-guerra, participaria da fundação do Partido Socialista e União Socialista Democrática, com Mário Pedrosa. Relembra: “o início do Estado Novo foi terrível. Nós falávamos a favor dos trabalhadores, da incipiente Legislação do Trabalho e dos direitos da mulher. Havia poucas moças na faculdade, pouco mais de 300 alunos por turma e no máximo umas 20 moças. (...) Éramos contra o status quo, queríamos mudança.” Evaristo de Moraes Filho. Entrevista. Apud: CACO: 90 anos de história. Coordenadoria de Comunicação da Universidade Federal do Rio de Janeiro. Rio de Janeiro: UFRJ, 2007. Disponível em: $<$ http://www.ufrj.br/sgcoms/docs/Memorabilia-CACO-90-ANOS-de-HISTORIA.pdf>.

${ }^{16}$ Nas Comissões Mistas, instituídas pelo Decreto 21.396, conciliava-se a matéria coletiva. Nas memórias do secretário Evaristo de Moraes Filho, há relatos sobre a combatividade de sindicatos cariocas. Indagado sobre a existência de muitas
} 
Foi professor contratado de Direito Industrial e Legislação do Trabalho, na Faculdade Nacional de Direito (FND) (1950-1951), ${ }^{17}$ de Direito Social, de Administração Pública, de Sociologia do Direito (1952), professor de Direito Público Especializado, tendo atuado como docente de Relações Humanas na Indústria, na Confederação Nacional dos Trabalhadores na Indústria (1955-1956). Sua cátedra de Direito do Trabalho foi obtida em 1957, com a defesa de "O Contrato de Trabalho como Elemento da Empresa" (MORAES FILHO, 1993), após ter sido aconselhado a não apresentar a tese desenvolvida em seu " $O$ problema do Sindicato Único no Brasil” à Congregação da FND, o que sugere como as dificuldades de reconhecimento pelo campo jurídico de abordagens sociológicas são de longa data. À época, Evaristo havia concluído a Faculdade de Filosofia, onde lecionara e assistira aulas de sociologia com Georges Gurvitch. A formação múltipla permitiu sua integração aos órgãos interdisciplinares criados na Universidade do Brasil, dentre os quais o inovador Instituto de Ciências Sociais (ICS) (AMORIM, 2007). Sua vida universitária, com as cátedras de sociologia e de direito do trabalho e a presidência do ICS, foi acompanhada de intensa prática jurídica, inicialmente como funcionário público, como Procurador do Trabalho ou na assessoria jurídica do ministério.

Com mais de 70 livros e 280 artigos publicados, ${ }^{18}$ à doutrina de Evaristo de Moraes Filho se somam seus pareceres e anteprojetos de lei. Vale lembrar sua participação na Comissão Afonso Arinos, instituída para redigir um anteprojeto de Constituição (a Comissão dos Notáveis, em 1986), bem como na Comissão Revisora do Anteprojeto do Código Processual do Trabalho (1963-1964), durante o governo João Goulart. ${ }^{19}$ Na ocasião, foi

demandas, afirmou: "Mais ou menos... Havia muita greve. Os bancários estavam numa fase de extrema combatividade. (...) Já havia desemprego, e a alternativa que se discutia era a mesma de hoje: redução da jornada de trabalho. Categorias mais combativas, empregados nas indústrias de calçados, tecidos, o pessoal do setor de alimentação, bancários e funcionários da Standard Oil, viviam em greve. O movimento sindical tinha muita energia! Em contrapartida, o Ministério detinha muito poder. (...) As convenções coletivas de trabalho eram elaboradas pela Comissão Mista: a duração da jornada, o período de férias, as indenizações... Os industriários tinham direito a indenizações e à estabilidade desde que o Congresso aprovara a Lei n. 62, de 5 de junho de 1935. Antes, portanto, de Getúlio começar a legislar por decreto-lei” (MOREL; GOMES; PESSANHA, 2007, p. 71-72).

${ }^{17}$ A ambiência na Nacional de Direito seria profundamente afetada com a ditadura estadonovista e em 1953 quando Evaristo retorna para prestar concurso de livre-docente encontraria uma faculdade decadente, "rumando para a direita". Sobre o efeito que as ditaduras provocaram para a desconstrução da Faculdade Nacional de Direito, registramos o depoimento de Evaristo: "Qual foi à repercussão do Estado Novo, em 37, no ambiente da faculdade? EMF: Foi terrível, uma tristeza! Não houve intervenção na faculdade, mas os professores de tendência esquerdista foram afastados. Então, a faculdade começou a contratar pessoas sem concurso e a qualidade caiu muito. Mas o Estado Novo foi repelido". E ainda: "Eu voltei como livredocente em 53 e como catedrático em 57. O quadro estava triste! O Castro Rebelo se aposentou em 54, aos 70 anos. O Hermes Lima era deputado no Palácio Tiradentes e a faculdade estava caminhando para a direita. Aqueles professores que o Getúlio contratou fizeram concurso e ficaram. Estava bem diferente, muito decadente.” Evaristo de Moraes Filho. Entrevista. Apud: CACO: 90 anos de história. Coordenadoria de Comunicação da Universidade Federal do Rio de Janeiro. - Rio de Janeiro: UFRJ, 2007. Disponível em: < http://www.ufrj.br/sgcoms/docs/Memorabilia-CACO-90-ANOS-de-HISTORIA.pdf>. ${ }^{18}$ Para acesso à bibliografia jurídica, ver: <http://www.bvemf.ifcs.ufrj.br/producao_intelectual.htm\#direito>.

${ }^{19}$ O Anteprojeto de Código do Trabalho, redigido por Evaristo de Moraes Filho, foi apresentado a João Mangabeira, Ministro da Justiça e Negócios Interiores, em 31 de março de 1963. Pretendia representar a legislação "a forma jurídica adequada para formular e apressar a mudança social”, afirmara Evaristo de Moraes Filho que em seus estudos iniciais - nos quais se referenciando em economistas desenvolvimentistas, como Celso Furtado e Inácio Rangel, imbuído do pressuposto de que o 
redator do Anteprojeto do Código do Trabalho, encomendado pelo Ministério da Justiça e considerado por Elina Pessanha como peça central para o entendimento de suas posições “sobre a natureza das relações de trabalho em nosso país”, na qual externou “o conteúdo democrático e universalista dessas posições” e demonstrou “ampla erudição na área de reflexão social” (PESSANHA, 2005, p. 149).

\section{CONTRIBUIÇÃO À SOCIOLOGIA E AO DIREITO COLETIVO DO TRABALHO}

No campo do pensamento social brasileiro, a singularidade dos estudos de Evaristo de Moraes Filho é reconhecida. "Pensador nodular capaz de amarrar tradições distintas e conflitantes do pensamento brasileiro” afirma José Murilo de Carvalho, Evaristo opera um “exercício de criatividade” para o que teriam contribuído três variáveis:

O socialismo democrático (...), entendo-se por essa expressão a preocupação com o social, via questão trabalhista, aliada à valorização da liberdade; a interdisciplinaridade, conectando direito, filosofia e sociologia; e a estreita vinculação entre a atividade intelectual e a prática profissional e política. (CARVALHO, 2005, p. 43).

Parece-nos que tais aspectos influenciaram sobremaneira o seu modo de ver e pesquisar o Direito do Trabalho. Diante da vastidão de sua obra para a consolidação teórica do Direito do Trabalho no Brasil, cabe uma reflexão sobre o reconhecimento de sua importância. Se, por um lado, certa negligência com a qual é tratado pelos juristas se explica pela aposentação compulsória e trajetória de crítica ao autoritarismo do Estado Brasileiro e suas ditaduras, por outro, as dificuldades de reconhecimento de suas ideias podem ser relacionadas ao caráter precursor de suas teses. Segundo Glaucia Villas Bôas, Evaristo remou contra a maré, “contra as interpretações canônicas estabelecidas” tanto no direito quanto na sociologia, sendo necessário conferir às ideias o papel de relevo que lhes cabe no pensamento social (2005, p. 61-63).

O instrumental sociológico manejado se distinguia dos quadros teóricos em voga em seu tempo, marcados por leituras totalizantes ou referidos à mudança social. ${ }^{20} \mathrm{~A}$ opção de

Brasil vivenciava uma etapa específica "em fase de arranco (take-off) para o desenvolvimento", destacara "a necessidade de se transformar em regra jurídica aquilo que a sociedade solicita para a realização do seu crescimento” (1963, p. 33). Destacase na proposição do Anteprojeto: a extinção do enquadramento sindical, a livre formação de entidades de cúpula, gerais, a sindicalização do funcionalismo público, a proibição da intervenção administrativa na vida sindical, a interveniência do Ministério Público nas relações entre sindicatos e Administração, a instituição do delegado sindical nos conselhos de empresa, a revogação do imposto sindical (PESSANHA, 2005).

${ }^{20}$ Conforme bem observa Glaucia Villas Bôas: “Ao contrário de tantos contemporâneos seus, não desqualifica o passado, mas volta a ele para evidenciar o conjunto de ações, movimentos, greves e paralisações cujo desenrolar provocou mudanças 
Evaristo pelo conceito de grupo social (em vez de classe social), o deslocamento do lugar privilegiado ocupado pelo Estado em relação às análises da época, ${ }^{21}$ seu afastamento das teses de inversão sindical brasileira e do mito sobre a incapacidade dos brasileiros são outros aspectos particulares da produção de Moraes Filho.

Na área do direito, sabemos o quanto a dogmática persiste como método de análise hegemônico e não temos dificuldades em reconhecer o pioneirismo de uma compreensão do direito como fato social e dos fundamentos sociológicos utilizados para explicar os institutos jurídicos e os processos de criação normativa. Neste contexto, para além dos posicionamentos políticos democráticos, há que se destacar que o autor em discussão:

Posicionou-se contra as teses formalistas sobre a prática legislativa da teoria do
direito; e contra as teses sobre o insolidarismo do caráter nacional ou ethos
brasileiro. A elas opôs uma teoria sociológica pragmática, em que associação,
interesse e ação são elementos fundamentais. Esse arranjo de ideias cunha seus
argumentos voltados para a desmistificação do mito da outorga das leis trabalhistas.
Retirando o Estado de seu lugar de portador de toda ordem, modernidade e
progresso, e delegando aos sujeitos sociais a capacidade de lutar pelos seus
interesses, Evaristo de Moraes Filho devolve aos trabalhadores brasileiros a sua
maioridade. (VILLAS BÔAS, 2005, p. 82).

Quando ainda na década presente, circulam em ambientes profissionais e universitários ideias que negligenciam o papel dos sindicatos e dos trabalhadores como atores na configuração do Direito do Trabalho brasileiro, em que o senso comum teórico dos juristas oscila entre a desconsideração, a culpabilização, a afirmação de ausência de representatividade dos sujeitos sindicais e o discurso de crise dos sindicatos, sem maiores reflexões sobre os pressupostos e limites teóricos e analíticos de tais assertivas, vale resgatar as críticas de Evaristo de Moraes Filho aos mitos do consenso, da cordialidade do brasileiro, da outorga ${ }^{22}$ e de um Estado benefactor (FRENCH, 2001, p. 83). A atualidade das orientações de Evaristo de Morais Filho, para as ciências sociais em geral e para a sociologia do trabalho,

efetivas nos direitos dos trabalhadores. Além disso, a abordagem dos sindicatos e associações operárias enquanto grupos profissionais que agem e interagem e, portanto, fazem sociedade na acepção da sociologia de Simmel (Vergesellschaftung) livrou o sociólogo da medida de avaliação da sociedade brasileira, largamente utilizada na época, dada pelos pares conceituais status/contractus Gemeindschaft/Gesellschaft, cultura folk/civilização que dividiam a sociedade em duas ades.” (2005, p. 64).

21 "Não é preciso ir muito longe para perceber que o argumento do autor incide no deslocamento do Estado do lugar privilegiado que ele assume como móvel de construção da sociedade. As regras do direito não fundam as instituições, ao contrário são as instituições que fazem as regras do direito (1978, p. 195). Contudo, a perspectiva sociológica de Evaristo de Moraes Filho não repercute apenas na revisão da eficácia das normas jurídicas e seus efeitos sociais. Ao posicionar-se contra o mito da outorga das leis trabalhistas no Brasil e contrariar as teses da ciência do direito que reconhecem no Estado a única fonte do direito, apostando na ascendência do ordenamento jurídico, no "fazer sociedade", questiona uma das mais bem consolidadas interpretações sobre o país, que diz respeito ao poder (quase único e absoluto) do Estado na construção da nação da sociedade.” (VILLAS BÔAS, 2005, p. 76).

22 “(...) não houve outorga nenhuma, como quem dá esmola a um débil mental. As massas operárias lutaram durante um triênio - e ainda lutam hoje e continuarão a lutar - pelo advento de leis que lhes melhorassem as condições de vida. Houve greves, lutas, sangue, desespero, prisões, morte. Como falar-se em pobres-diabos, sem líderes, sem ideias, sem aspirações que receberam tudo que se lhes queria dar como favores espontâneos e unilaterais.” (MORAES FILHO, 1978). 
é sublinhada por José Ricardo Ramalho, “principalmente no alerta contra o perigo que correm analistas de minimizar a capacidade de intervenção relevante desses atores sociais no processo de discussão da legislação trabalhista e sindical” (2005, p. 238).

É em O Problema do Sindicato Único no Brasil (1952), livro escrito para postular a livre-docência em Sociologia, que as concepções sobre a capacidade de ação dos trabalhadores e dos sujeitos coletivos são explicitadas. Antes de escrevê-lo, Moraes Filho se debruçara sobre O Problema de uma Sociologia do Direito, no qual dialoga com os teóricos que construíam esta nova disciplina. Imbuído das questões sobre as quais se debruçava esta primeira sociologia jurídica, tais como a oposição entre monismo e pluralismo jurídico, a importância da ordem interna das organizações sociais, o problema da eficácia das normas e seus efeitos sobre o comportamento humano, a compreensão do direito como fato social, partiu Evaristo de Moraes Filho para especificar tal metodologia de análise com o estudo do grupo social e do sindicato. Assentadas as premissas teóricas para uma abordagem sociológica do fenômeno jurídico, o livro provocaria uma reviravolta nas explicações correntes sobre a legislação e a estrutura sindical, marcadas pelo apego excessivo ao formalismo e ao paternalismo, embora tenha tido repercussão tardia.

Segundo Ângela Castro Gomes (2003), apesar da tese principal do livro ser “a de que o sindicato deve ser entendido como um grupo funcional ou de interesse, espontâneo e derivado da moderna realidade socioeconômica, não precisando do Estado para se constituir e existir”, seria a interpretação das relações entre Estado e Sindicato que adquiriria forte ressonância no contexto da redemocratização brasileira. Neste período, O Problema do sindicato único no Brasil fora republicado, contribuindo de modo significativo para uma releitura sobre a história do movimento sindical, de seu papel na construção do direito do trabalho, com o resgate das regulações costumeiras anteriores à Era Vargas e da ideologia estadonovista, promovidas por diversos precursores da legislação reformista. Assim, é importante revisitá-lo.

O Problema do Sindicato Único no Brasil é composto de quatro capítulos. Nos dois primeiros, encontramos os conceitos de profissão, ocupação, sindicato e de grupo social, apresentado como unidade social básica e objeto próprio da sociologia. A partir da industrialização e da moderna divisão social do trabalho, ocorre o aparecimento de profissões cada vez mais diferenciadas e estruturadas. A profissão é um grupo social espontâneo, empírico e natural, enquanto os sindicatos são instituições sociais capazes de organizá-las: podemos quase afirmar que o sindicato é a forma, cuja matéria é constituída pela profissão concreta dos indivíduos que a exercem (MORAES FILHO, 1978, p. 70). 
Sindicato único, unicidade, pluralidade, liberdade e autonomia sindical são temas recorrentes no debate sobre estrutura sindical brasileira. A opção do autor pelo sindicato único como forma de organização das profissões advém de sua visão espontânea do agrupamento social e é anunciada logo na introdução: "Se a profissão, o grupo, a categoria social é una, indivisa, homogênea; uno, indiviso, homogêneo deve ser igualmente o sindicato” (MORAES FILHO, 1978, p. 8). A profissão é o critério adotado pela maioria das legislações estrangeiras para definir a organização das entidades sindicais, sendo, pois, admitida a intervenção estatal para resguardar que todos os sindicatos sejam constituídos conforme este critério básico. Se assim o é, também pode ser justificada a adoção do regime legal do sindicato único por profissão. Embora, para Evaristo de Moraes Filho, autonomia e unidade não sejam termos inconciliáveis, sua proposta não é simples monopólio representativo pela unicidade, já que a busca por unidade não pode significar a estagnação das estruturas, tendo em vista que “o quadro sindical deveria ser móvel, plástico, dúctil” (MORAES FILHO, 1978, p.272). Saber como assegurar a unidade da profissão sem estagnar a vida sindical, sem perenizar os sindicatos instituídos é uma problemática que permanece atual. ${ }^{23}$

A defesa do sindicato único se estrutura como consequência de uma compreensão dos grupos sociais e da profissão como fatos sociais, bem como da sua compatibilidade com os regimes democráticos. Por serem os grupos profissionais grupos naturais, células do corpo social, seria possível que a legislação estabelecesse a unidade da representação jurídica da profissão em um sindicato único. A relação entre Estado e sindicato é o tema do terceiro capítulo, que reconhece manifestações de pluralismo jurídico, presentes nos regulamentos de empresa, nas conciliações de greve, nos conflitos coletivos de trabalho, oriundos da normatividade que emana das instituições intermediárias da sociedade. Como os sindicatos são formas organizativas anteriores à sua incorporação pelo mundo jurídico, não são instituídos pelo Direito e, como são dotados de normatividade, há que se reconhecer a fragilidade das teorias jurídicas que se filiam ao monismo.

Com o reconhecimento estatal dos sindicatos, surge o problema de saber em que medida a atividade das organizações está imune à autoridade e ao controle governamental.

\footnotetext{
${ }^{23}$ Partindo da distinção entre sindicato único e sindicalização obrigatória, Evaristo defende que a pulverização dos sindicatos é evitada pela unidade da profissão, fato social reconhecido na maioria dos países examinados. Porém, a unidade da profissão não se garante apenas pela organização sindical única, mas também através da unidade de seus instrumentos de ação, as convenções e os conflitos coletivos de trabalho. O "caos sindical” pode ser evitado com um sistema plural, desde que seja estabelecida a entidade sindical mais representativa - a partir da sua importância, atividade e independência - que deterá prerrogativas especiais distintas de representação da profissão, já reconhecia Evaristo de Moraes Filho com base no estudo da experiência francesa, em que há uma pluralidade de direito sim, mas uma unidade de fato. A mobilização deste argumento demonstra não só sua sofisticação, como também a sua atualidade. Basta lembrar que vários dos critérios inerentes ao sistema de sindicato mais representativo foram adotados pelo Fórum Nacional do Trabalho, em especial a possibilidade de verificação da representatividade sindical periodicamente, e não apenas no momento inicial de constituição do sindicato.
} 
Mais que descrever o conteúdo da autonomia sindical, Moraes Filho reflete sobre os limites da autonomia nas sociedades democráticas, problematizando o entrosamento das “associações profissionais, gozando de autonomia administrativa e estatutária, no mecanismo funcional do Estado, sem sufocar as livres manifestações da sua espontaneidade social” (MORAES FILHO, 1978, p. 144).

A legislação trabalhista brasileira é o tema do quarto e último capítulo. Coerente com a proposta de sua sociologia do direito, a regulação é apresentada a partir de sua construção histórico-social e com ênfase na efetividade das normas estabelecidas. Se o direito não surge do Estado, mas nasce do interior da sociedade e da ordem interna das organizações, a afirmação de que a legislação social brasileira teria sido outorgada pelo governo Vargas não pode ser aceita sem maiores verificações. Coerente com seus pressupostos, Evaristo estuda a atividade pró-regulação do trabalho (entre 1891 até o final da década de 1940), examina projetos legislativos apresentados no Congresso, programas dos partidos políticos, greves, manifestações etc. com o que afirmava o equívoco histórico do que posteriormente seria denominado de "mito da outorga": a construção getulista de que o direito laboral teria sido obra e beneplácito do Estado Novo. ${ }^{24}$ Este é, sem dúvida, o aspecto mais destacado pelos analistas, principalmente por refutar a ideia da incapacidade do brasileiro como ator. Como Elina Pessanha afirma:

\begin{abstract}
Caudatária de diferentes tradições teóricas, sua obra persegue persistentemente a questão do protagonismo histórico da ação dos homens, sem perder de vista as possibilidades de mudança social que se abrem sob pressão de forças necessariamente coletivas. Nesse sentido, as normas, traduzidas em mecanismos de controle social - eventualmente protegidos pelo Direito -, seriam na verdade 'produzidas' no plano da vontade e da possibilidade política dos agentes sociais. (PESSANHA, 2005, p. 158).
\end{abstract}

No campo da cultura jurídico-trabalhista, a concepção contra-hegemônica proposta é patente. Não são os juristas e intelectuais, nem o é o Estado e o governante, os propulsores da construção do novo direito. A uma concepção profundamente autoritária de organização jurídico-sindical, de nação e de Direito, imbuída de um elitismo próprio de um tempo cujas elites recusavam às classes populares qualquer significação e diante de uma modernização autoritária, Evaristo opõe leitura distinta, em um contraponto não liberal, mais afinada com um paradigma jurídico que começava a dar sinais nos países da Europa continental ocidental de seu tempo, em um momento de transição de um protecionismo clássico para o

\footnotetext{
${ }^{24}$ Para Paulo Sérgio Pinheiro, Moraes Filho foi o precursor na crítica à tese da outorga da legislação trabalhista pelo governo Vargas (1978).
} 
protecionismo promocional (FREITAS JÚNIOR, 1999, p. 66-75), com instrumentos normativos e concepções jurídicas características do Estado Providência. ${ }^{25}$

Trata-se de uma concepção que "reivindica a modernidade para o Estado legislador” (VILLAS BÔAS, 2005, p. 77). Afinal, é no período inicial dos anos gloriosos da regulação do trabalho na Europa que Evaristo desenvolve suas teses e publica suas obras mais relevantes no Brasil.

\section{O DIREITO DO TRABALHO VISTO POR EVARISTO DE MORAES FILHO}

Clássicas são as discussões sobre natureza jurídica, autonomia e posicionamento do Direito do Trabalho dentre os ramos jurídicos para as quais a tradição da dogmática jurídica se volta. ${ }^{26}$ Evaristo não foge a tais debates e em Introdução ao Estudo do Direito se situa claramente ao adotar um “conceito misto ou complexo do direito do trabalho” por agregar aos aspectos objetivos de uma disciplina, aspectos subjetivos, que singularizam o ramo trabalhista. Abstrair os indivíduos e as coletividades [que remetem aos sujeitos da relação jurídica] "seria a própria negação da razão de ser da constituição do novo direito: desenganadamente intervencionista a favor de um dos lados da relação, para equilibrá-la e exatamente pela sua posição de inferioridade econômica e social” (MORAES FILHO, 1951, p. 50).

Moraes Filho enfrenta o problema da qualificação dos titulares das relações jurídicas como intrínseca ao Direito do Trabalho, tanto para a aplicação dos conteúdos quanto para definir a extensão de sua incidência. A desigualdade econômica dos sujeitos é constituinte de sua definição de direito do trabalho, que não se limita às relações jurídicas entre os sujeitos do contrato, mas se espraia para múltiplos aspectos provenientes daquela relação, ${ }^{27}$

\footnotetext{
${ }^{25}$ Registro, com Glaucia Villas Boas, que (...) "seria um equívoco pensar que, ao se posicionar contra o mito da outorga, atribuindo maioridade aos trabalhadores e restringindo com sua argumentação, o poder e a força do Estado, Evaristo desconsidere o papel do Estado. O que advoga é a mudança na concepção do papel do Estado. A lei é o fundamento da autoridade legítima do Estado e, para que se possa legislar de acordo com as especificidades da sociedade moderna, é preciso que se acabe com a crença na infalibilidade e soberania única do Estado. Tal prepotência perde sua razão de ser nos tempos modernos.” (2005, p. 76).

${ }^{26}$ Dogmática no sentido que lhe emprega Evaristo, como resultado de uma sistematização racional do trabalho científico do jurista: "Não hesita a doutrina em optar pelo termo direito, em vez de legislação. Em verdade, constituiu-se de há muito uma autêntica ciência do direito do trabalho, que reduz a sistema a legislação trabalhista, penetrando-lhe os motivos, as razões constitutivas, expondo-lhe as conexões íntimas, as repercussões sociais, os desenvolvimentos e as tendências, além de uma visão histórica do conjunto, abrangendo os institutos singulares e sua exata compreensão. Constrói-se cada vez mais uma acabada e coerente dogmática do direito do trabalho.” (MORAES FILHO, 1965, p. 51).

${ }^{27}$ Cf. definição proposta "Compreendemos, pois, como Direito do Trabalho o conjunto de princípios e de normas que regulam as relações jurídicas oriundas da prestação de serviço subordinado e outros aspectos dêste último, como consequência da situação econômica das pessoas que o exercem.” (MORAES FILHO, 1951, p. 50, grifos originais). Observe-se que o objeto não é a relação de emprego, são relações jurídicas múltiplas, por isto outros aspectos derivados da vida do trabalho como decorrência do status social e econômico se inseriam no direito do trabalho. A visão expansionista quanto à matéria envolve aspectos previdenciários (pensões, auxílios-doença, morte, funeral etc.), de assistência social
} 
prenunciando as tendências contemporâneas de ampliação dos círculos dos sujeitos protegidos. $^{28}$

Contudo, suas preocupações dogmáticas não dizem respeito ao estudo e comentários de regras e institutos específicos. Nos dois volumes de Introdução ${ }^{29}$, temos uma Teoria Geral do Direito do Trabalho, ancorada em discussões conceituais sobre o Direito, no capítulo 1, e sobre o Trabalho, no capítulo 3, no qual, com uma abordagem interdisciplinar, enfrenta o debate etimológico, enquanto expressão cultural de cada tempo: para observar a tradição carregada de valores penosos ou depreciativos, de uma locução rica de significação e ambiguidade. Estuda a dimensão da ciência do trabalho como uma antropologia, "sendo o trabalho inseparável do homem”, a totalidade da pessoa humana envolvida no trabalho como homo faber em luta com a natureza, transformando-a. Reflete sobre a especificidade do que é trabalho vivo , sem deixar de registrar uma leitura mais ampliada da natureza produtiva do trabalho humano não somente como transformação de matéria-prima; e para situar a especificidade da formação do proletariado e do exército de reserva como elementos novos do sistema capitalista, assentado nos conceitos de trabalho livre e mercado livre, a partir de Marx, mas principalmente das análises de Weber.

Com um objeto delimitado no fenômeno do assalariamento e a partir do diagnóstico sobre suas consequências para a vida do trabalhador, Evaristo apresenta as características do Direito do Trabalho como um direito em vir a ser:

Em resumo, estes são para nós os caracteres fundamentais do direito do trabalho como ramo autônomo e especial da ciência jurídica: a) é um direito in fieri, um werdendes Recht, que tende cada vez mais a ampliar-se; b) trata-se de uma reivindicação de classe ou de um direito de classe; é intervencionista, contra o dogma liberal da economia, por isso mesmo cogente, imperativo, irrenunciável; d) é de cunho nitidamente cosmopolita, internacional ou universal, e) os seus institutos mais típicos são de ordem coletiva ou socializante; f) é um direito de transição, para uma civilização em mudança. (MORAES FILHO, 1965, p. 31-32).

\footnotetext{
(moradia, lazer, assistência judiciária), inclusive acenando com políticas sociais (“amplia-se o campo do direito do trabalho, trazendo para seu âmbito tutelar um número cada vez maior de pessoas, que vivam de salário ou não disponham de renda própria, capaz de lhes assegurar uma auto-suficiência frente aos riscos de uma vida normal na sociedade dos nossos dias”) em uma leitura mais holística de ramo que se volta à justiça social, ocupando-se da "vida do trabalhador, antes, durante e depois da relação de emprego”, voltado para o “máximo de bem-estar, de felicidade geral.” (MORAES FILHO, 1951, p. 57). 28 Ao analisar o conceito de subordinação ou dependência como intrínseca à relação de emprego, registra que "não quer isto dizer, no entanto, que o direito do trabalho não se ocupe com o denominado trabalho autônomo, mas cuida primacialmente do chamado trabalho subordinado." (MORAES FILHO, 1951, p. 55), mas reafirma que "embora a tendência do direito do trabalho seja no sentido de abranger todas as formas de prestação de serviços, subordinada ou não, não há como negar que ainda hoje se coaduna mais propriamente com a proteção ou tutela do trabalho dependente.” (Ibidem, p. 104). Em 1965, reafirma a tendência registrando, todavia que entre nós, "neste particular, em grande atraso". (Idem, 1965, p. 60).

${ }^{29}$ O primeiro volume com 473 páginas, divididas em quatro títulos: o conceito e sistematização, os fundamentos e a formação histórica do direito do trabalho, a autonomia do direito do trabalho; e o segundo volume, com 538 páginas, volta-se ao debate da posição sistemática do direito do trabalho (entre o público e o privado, com obliteração das fronteiras entre os campos), sua natureza jurídica e as relações com os demais ramos jurídicos, exclusivamente.
} 
Como "sinais que vão marcando a existência deste direito", o dinamismo e a contínua transformação são as características que Evaristo observa no ramo em consolidação, por meio do confronto entre duas pretensões valorativas que se contrastam, a de segurança jurídica, base da individualista organização jurídica do capitalismo, e a de justiça, como a busca pela redistribuição de bens sociais: "Em nenhum outro direito se encontra tão dramática e intensa esta sede de justiça distributiva como no direito do trabalho.” (MORAES FILHO, 1965, p. 13). Entre as demandas por segurança jurídica e por justiça se constrói o direito do trabalho, com a plasticidade e historicidade que lhe são próprias e inspirado por demandas de redistribuição.

A especialidade, Evaristo justifica reconhecendo, com Durand, que "a importância do direito do trabalho não é a mesma para todos”, motivo pelo qual “se diz ser um direito de classe”, da categoria de pessoas que cumprem um contrato (1965, p. 34-35). Posiciona-se com um prognóstico de que:

(...) enquanto existir a sociedade capitalista sob sua forma atual, claramente dividida em classes econômicas, formando uma verdadeira hierarquia na pirâmide da estratificação social, é de todo impossível esvaziar o direito do trabalho deste conteúdo tutelar e ostensivamente protetor. (MORAES FILHO, 1965, p. 36.).

O particularismo de um direito novo derroga, assim, o que com ele for incompatível, o direito comum. Observo que, enquanto na sociologia seu conceito de grupo social é manejado para explicar o sindicato (e, neste sentido, sua recusa ao corporativismo, já que a organização sindical não é uma decorrência de uma noção normativa de categoria), em seus estudos jurídicos, a categoria de classe social é manejada para explicar o Direito do Trabalho, ainda que para ultrapassá-la, como veremos na discussão sobre os fins da legislação trabalhista.

Mais que reivindicação de classe, o intervencionismo é sua nota distintiva, faceta do abandono do papel absenteísta que se transforma em "Estado positivo", para mitigar consequências do regime capitalista. Nesta leitura, o Direito do Trabalho é imperativo, cogente, limitador da autonomia da vontade e desmistificador da igualdade: "suas normas não trazem a ilusão de que todos sejam iguais, tratam de propósito desigualmente a seres desiguais, tutelando uma categoria que precisava de sua proteção e a bem merece” (1965, p. 37). ${ }^{30}$ A nota de imperatividade se contrapõe à natureza dispositiva do direito civil do qual se

\footnotetext{
30 “O direito do trabalho é um direito imperativo, que limita deliberadamente a suposta liberdade de contratar, intervindo o Estado naquela esfera, outrora sagrada, da autonomia da vontade, da doutrina liberal. Escreve o Estado, com sua mão poderosa, a maioria das cláusulas do contrato de trabalho, sendo quase todas de interesse público, irrevogáveis e
} 
autonomiza. Todavia, nega Moraes Filho a existência de singularidade da pressão operária como fonte formal do Direito do Trabalho, como sustentara G. Lyon-Caen, à qual opõe o mesmo húmus social dos demais campos do direito e uma mudança de mentalidades. ${ }^{31}$

O caráter compromissório e de mediação é destacado por Evaristo como uma das consequências mais fortes da relação entre mudança social e direito do trabalho, com suas características de “democratização, de transição e transação", aquela primeira um senso comum à época. Não chega Evaristo a classificar o direito do trabalho como um direito do capitalismo, em sua ambiguidade, em seu caráter ambivalente e compromissório, como os franceses mais tarde o farão. Inscreve a tarefa do ramo juslaboral como de uma legislação entre "dois mundos sociais”, de transição entre uma antiga estrutura social e uma nova formação “que há de vir”. Impregnado por uma visão desenvolvimentista e profundamente otimista da história, Evaristo reputa ao Direito do Trabalho "realizar a revolução branca, a reforma social sem sobressaltos, nem alterações bruscas das atuais posições de vida.” (1965, p. 42-43). O socialista possibilista, de que nos fala Pessanha, centra como tarefa do Direito do Trabalho a de ser um mediador "entre classes sociais em luta”. É, pois, um direito de compromisso e mediação.

Definido o objeto amplo e as características específicas do Direito do Trabalho, Evaristo de Moraes Filho trabalha com finalidades heurísticas em três vertentes: as políticosociais, as econômicas ${ }^{32}$ e as jurídicas ${ }^{33}$. A distinção é didática, mas assim opta nosso autor. A

irrenunciáveis por pactos particulares. Se o direito civil é de natureza dispositiva (ius dispositivum), preenchendo simplesmente as lacunas deixadas em claro pela livre vontade dos contratantes - o contrato é a lei das partes, diz o velho refrão civilista - o direito do trabalho coloca-se em ponto diametralmente oposto, é um direito cogente (ius cogens), que determina desde logo a vontade dos indivíduos, regulando-lhes a conduta social, deixando para as partes unicamente o acessório.” (MORAES FILHO, 1965, p. 37).

31 "As fontes materiais do direito do trabalho se confundem com os seus próprios fundamentos concretos, racionais e históricos (...). Não podemos concordar com G. LYON-CAEN, quando escreve que o direito do trabalho decorre da pressão exercida pela ação reivindicadora dos trabalhadores (Manuel de Droit Du Travail et de La Sécurité Sociale, Paris, 1955, p. 22). Esse é, sem dúvida, um dos seus fundamentos, mas não o único. As fontes reais ou primárias do direito do trabalho originam-se do mesmo húmus social como as das outras espécies jurídicas. E nem poderia ser de outro jeito, mas constituiuse em espécie própria pelos motivos que se fizeram presentes na sociedade liberal nascida com a Revolução francesa. Essas fontes reais são de índole vária: econômicas, sociais, políticas, idealistas, religiosas, e assim por diante. Ao lado dos grupos de pressão houve também uma certa mudança de mentalidade”. (MORAES FILHO, 1965, p 181-182).

32 Dentre as finalidades econômicas imediatas, está a da garantia de uma remuneração mínima para permitir a subsistência por meio de uma vida digna e, dentre as mediatas e mais profundas, a participação dos empregados nos resultados, lucros da empresa, a organização do mercado da mão de obra, a proteção do trabalhador como competidor (Commons e Andrews), a organização das profissões em uma economia dirigida etc.

${ }^{33}$ Por fins jurídicos, denomina o autor as "medidas práticas e legais que o Estado toma em favor da efetivação daquelas finalidades econômicas, políticas, sociais e éticas oriundas de outras esferas, às vezes extrajurídicas.” (MORAES FILHO, 1965, p. 248), com realce para a mais elementar proteção ao trabalhador diante da desigualdade econômica existente para com os possuidores dos meios de produção, mas, acrescentando Evaristo, a tutela do próprio trabalho: "não poderia o direito do trabalho permanecer nestas finalidades protecionistas somente de uma classe, abandonado o próprio fato social trabalho, produto de mais de uma estratificação econômico-social e expandindo-se além, muito além, das relações concretas entre empregado e empregador (...) Assim, concluindo, através da tutela e da proteção que dispensa a um dos lados do binômio empregatício - ao trabalhador - realiza o direito do trabalho a sua principal finalidade jurídico-formal, tornando menos injustas as relações entre empregador e empregado, ao mesmo tempo que mais livres e igualitárias, atingindo assim, de modo indireto, a tutela do próprio fato social manifestado no trabalho, que se torna mais digno, mais produtivo, mais compensador.” (MORAES FILHO, 1965, p. 257-258). 
finalidade político-social se relaciona com seu caráter compromissório. Resultante direto do “conflito de estratificação social”, "surgido em meio a lutas políticas e sociais”, quando a força e a sufocação como meios extremos para impedir a revolução, surge o Direito do Trabalho "representando uma solução intermediária, um meio-termo de compromisso, de transação na luta entre as duas classes que se empenham na produção econômica”, com a função de modelar a forma da sociedade que surge do conflito de interesses, "como controlador das novas aspirações sociais.” (MORAES, 1965, p. 236).

A finalidade política do Direito do Trabalho como "válvula de segurança” não pode ser esquecida ou abandonada e, para tanto, sua finalidade de proteção e tutela aos trabalhadores. Não pode "recolher-se a uma atitude restrita de mero tecnicismo jurídico, de simples lógica jurídica, estranho aos motivos e às condições que lhe deram o primeiro impulso histórico”, afirma (1965, p. 235), trazendo a concepções que atribuem um caráter conservador ao ramo e outras que sublinham sua função de solidariedade. ${ }^{34}$ Seu viés integrador e sua crença na justiça como nota do direito faz com que proponha mecanismos para a crescente integração das classes na cena pública e, em especial, com duas finalidades específicas: de democratização da empresa, com a participação dos empregados na gestão (MORAES FILHO, 1965, p. 236) e de transformação do trabalhador em cidadão (MORAES FILHO, 1965, p. 240).

A caracterização de um Evaristo afinado com os debates e preocupações que inspiravam as vertentes pluralísticas e democráticas que reconfiguraram o Direito do Trabalho no continente europeu do pós-guerra encontra ressonância. Há indícios que permitem sugerir inscrevê-lo no campo de um constitucionalismo social revigorado.

Cumpre verificar se tais concepções singulares sobre as finalidades econômicas, jurídicas e políticas do Direito do Trabalho se expressam nas suas formulações legislativas e na interpretação das regras jurídicas. Com que institutos e regras se democratizam a empresa, moderniza-se o país e se possibilita ao trabalhador ser um cidadão ativo? Estabelecidos os fundamentos democráticos de um Direito transformador, inscrito na dinâmica econômica e orientado para a mudança social, o que se distancia das leituras que inscrevem nossa cultura jurídica juslaboralista unicamente nas tradições corporativas e autoritárias, cabe pesquisar e examinar as marcas deixadas pelo jurista na modelagem de nosso Direito. Para tanto, os caminhos estão abertos para estudos que ajudem a superar uma lacuna nas pesquisas sobre a

\footnotetext{
34 "Segundo Paul Pic, a legislação do trabalho é um meio de preservar a atual sociedade de qualquer perturbação, por concessões oportunas às legítimas reivindicações das massas. E Charles Gide a caracteriza como 'a economia de uma revolução'. Vários autores como Commons, Andrews, Pic, Scelle e Mahaim, veem no direito do trabalho a efetivação de um mínimo de solidariedade social em oposição ao antigo individualismo político.” (MORAES FILHO, 1965, p. 237).
} 
formação de nosso Direito do Trabalho, que, embora sempre inscrito em disputas políticas e hermenêuticas, permanece lacunoso quanto às proposições legislativas de reforma. Em um momento no qual a historiografia sobre o regime militar se volta a tentar compreender as múltiplas razões pelas quais o projeto autoritário triunfou em 1964, e estuda-se o apoio do empresariado ao golpe, compreender as reformas em discussão no governo Goulart e, dentre elas, as propostas de mudança na legislação do trabalho, parece-nos relevante. Localizar as permanências das reflexões de Evaristo de Moraes Filho na cultura jurídica trabalhista no país, inscrevendo-o na tradição dos reformistas democráticos, pode ajudar-nos a mapear os projetos não hegemônicos de modernização das relações de trabalho no Brasil.

\section{CONSIDERAÇÕES FINAIS}

Como “complexo linguístico, simultaneamente objeto e produto da cultura jurídica”, o Direito do Trabalho pode ser estudado pelos "significados normativos e interpretativos que em determinados momentos históricos levam a cabo a teoria e a prática jurídica dos juristas” (BAYLOS, 2014). Assim, o registro de aspectos que evidenciam a filiação de Evaristo à corrente contra-hegemônica do pensamento jurídico, com a recusa do monismo e do positivismo jurídico, sugerem adesão a concepções mais pluralistas, com uma fundamentação mais democrática para o Direito do Trabalho, em um ambiente de constitucionalizaçãoe de resgate de algumas das promessas de Weimar. O reconhecimento das demandas por distribuição econômica e de poder entre os grupos sociais é expressa na afirmação do caráter compromissório e de mediação do direito brasileiro.

Além desta discussão sobre a natureza e as funções do Direito do Trabalho, uma pauta de estudos sobre seus conceitos de contrato de trabalho e relação de emprego, suas proposições sobre seguridade e acidentes de trabalho inseridos no direito laboral, bem como os conselhos de empresa, a autonomia sindical e o direito de greve, pode ajudar não só a superar a lacuna de estudos sobre tais aspectos da obra de Evaristo de Moraes Filho, em sua ampla maioria voltados à questão sindical, mas também pode auxiliar na compreensão deste jurista como um representante significativo do pensamento protecionista democrático de primeira geração em nosso país - o que não é pouco, diante desta tradição silenciada-. Ademais, pode permitir uma reflexão sobre os motivos pelos quais o impacto de sua obra no 
Direito do Trabalho pós-redemocratização foi menor que nos estudos de sociologia do trabalho. ${ }^{35}$

O argumento exploratório que decorre deste ensaio é o de que a produção de relevo de Evaristo de Moraes Filho é caudatária de um tempo específico do Direito do Trabalho, desenvolvida no pós-guerra, em um momento singular do processo de constituição da racionalidade jurídico-laboral, matizada pelas especificidades decorrentes do espaço em que se encontra, marcado pela tradição latino-americana. Trata-se de uma ambiência em que os fundamentos da regulação jurídica são postos à prova, depois da queda do regime de Vargas e da promulgação da Constituição brasileira de 1946, e os sentidos e finalidades do direito estão em disputa.

Sem negligenciar os aspectos de continuidade existentes e a decisiva importância do substrato político e econômico que atua na constituição do direito laboral, é possível sugerir que as transformações no papel do Estado e do Direito, no pós-segunda guerra mundial, influenciaram na reconfiguração dos sistemas normativos e cultura dos juristas. ${ }^{36}$ Neste contexto, as reflexões de Evaristo de Moraes Filho se inserem claramente dentro de tal sistematização, distanciando-se das visões unitárias das ideologias jurídicas e inspirando-se em proposições pluralísticas.

O presente artigo exploratório pretendeu apresentar a singularidade do pensamento não canônico de Evaristo de Moraes Filho, no debate sobre a estruturação do Direito do Trabalho brasileiro nas décadas de 1950 e 1960, a partir da explicitação sobre o papel dos sujeitos coletivos e grupos sociais, no direito coletivo do trabalho, e sobre as funções e finalidades do então novo direito em consolidação.

O particularismo da reflexão de Evaristo indica que há, também no Direito do Trabalho, um profícuo campo de pesquisa sobre sua abordagem, sobre o contrato de trabalho, a integração do homem na estrutura da empresa, os conselhos de empresa e de sua influência nos processos legislativos e na construção jurisprudencial. As relações entre sua abordagem sociológica e o deslocamento de seu olhar do Estado para os sindicatos e empresas e a concepção sobre o papel do jurista e do trabalho na sociedade brasileira permanecem como campos abertos de estudo. No entanto, para compreender os projetos silenciados, vencidos politicamente e pela força, de um direito que poderia ter sido e que, na sua ausência, explica

\footnotetext{
${ }^{35}$ Registre-se que somente no final dos anos 1980, propostas assemelhadas ao protecionismo garantista ou promocional passam a se difundir no campo jurídico brasileiro.

${ }^{36}$ Que se inicia com o alargamento do constitucionalismo social e se desenvolve com a atividade da Organização Internacional do Trabalho - OIT, refundada após Declaração de Filadélfia e sua integração no sistema das Nações Unidas ONU.
} 
por contraponto a cultura jurídica e o desenho atualmente existente no nosso ordenamento jurídico laboral, persiste para o pesquisador a tarefa de estudar as proposições legislativas do jurista Evaristo de Moraes Filho.

Para prosseguir neste debate, pontuando as proposições legislativas de cada época, cabe pesquisar o Anteprojeto de Código do Trabalho apresentado em 1963 a João Mangabeira, Ministro da Justiça e Negócios Interiores do governo interrompido de João Goulart, seus pressupostos, conceitos, institutos, princípios e instituições de resolução de conflitos. A utopia do juslaboralista brasileiro, concretizada em sua atuação como desenhista institucional, interrompida pelo regime militar, contribui para a reflexão sobre os fundamentos, democráticos e autoritários, do ordenamento jurídico que ainda temos. Talvez seja insuficiente um percurso de pesquisa que se preocupe em situar os fundamentos democráticos de um autor representante de uma determinada cultura jurídica, de toda sorte, quando se sabe que a naturalização da ideia de que o Direito do Trabalho seria autoritário porque não compreende o protagonismo dos sujeitos coletivos e se ampara em um discurso de hipossuficiência paternalista - circula com folga dentre vertentes do neoconstitucionalismo brasileiro, sendo manejado no âmbito da jurisdição constitucional para desconstruir os fundamentos democráticos de uma participação coletiva ativa, no campo de relações assimétricas de poder, $^{37}$ revisitar leituras contra-hegemônicas pode auxiliar-nos a desnaturalizar o que a disputa de sentidos em torno das normas trabalhistas traz em si, a disputa sobre a distribuição e redistribuição dos bens e do acesso à fruição adequada de recursos que permitem a existência do homem, dito de outro modo, sobre justiça distributiva e democracia.

\footnotetext{
${ }^{37}$ Segundo concepção utilizada pelo Supremo Tribunal Federal para fixar tese jurídica no sentido de validar a quitação geral dos direitos trabalhistas quando houver adesão a Plano de Dispensa Voluntária fixada por norma coletiva. Transcreve-se "Há, por outro lado, um modelo de normatização marcadamente heterônoma, que segue um padrão corporativo autoritário, que rejeita a autocomposição e a produção de normas privadas, através da submissão do conflito trabalhista ao rigoroso controle do Estado, direta ou indiretamente, no último caso, por meio de uma legislação minuciosa, que procura se antecipar e/ou eventualmente sufocar o embate entre empregadores e trabalhadores. Nesse caso, a disciplina das relações de trabalho provém fundamentalmente do Estado. Os exemplos clássicos de tal padrão são as experiências da Itália fascista e da Alemanha nazista, no século XX, com influência em outros países, entre os quais, reconhecidamente, o Brasil (...) Diferentemente do que ocorre com o direito individual do trabalho, o direito coletivo do trabalho, que emerge com nova força após a Constituição de 1988, tem nas relações grupais a sua categoria básica. O empregador, ente coletivo provido de poder econômico, contrapõe-se à categoria dos empregados, ente também coletivo, representado pelo respectivo sindicato e munido de considerável poder de barganha, assegurado, exemplificativamente, pelas prerrogativas de atuação sindical, pelo direito de mobilização, pelo poder social de pressão e e greve. No âmbito do direito coletivo, não se verifica, portanto, a mesma assimetria de poder presente nas relações individuais de trabalho. Por consequência, a autonomia coletiva da vontade não se encontra sujeita aos mesmos limites que a autonomia individual.” SUPREMO TRIBUNAL FEDERAL. Direito do Trabalho. Acordo coletivo. Plano de Dispensa Incentivada. Validade e efeitos. Recurso Extraordinário 590.415 Santa Catarina. Relator: Luis Roberto Barroso. Plenário.30 de abril de 2015.
} 


\section{REFERÊNCIAS BIBLIOGRÁFICAS}

AMORIM, Maria Stella de. Um jurista com vocação institucionalizadora das ciências sociais. In: PESSANHA, Elina; VILLAS BÔAS, Glaucia: MOREL, Regina (Org.). Evaristo de Moraes Filho, um intelectual humanista. Rio de Janeiro: ABL, Topbooks, 2005, p. 261300.

APARÍCIO, Joaquín.; BAYLOS GRAU, Antonio. (Org.). Weimar y Después? In: Autoridad y democracia en la empresa. Madri: Trotta, 1992.

BAYLOS GRAU, Antonio (Org.). Modelos de Derecho del Trabajo y Cultura de los Juristas. Albacete: Bomarzo, 2014.

BRASIL. Supremo Tribunal Federal. Plenário. Direito do Trabalho. Acordo coletivo. Plano de Dispensa Incentivada. Validade e efeitos. Recurso Extraordinário 590.415/SC. Relator: Ministro Luis Roberto Barroso. Data de julgamento: 30 de abril de 2015.

CARVALHO, José Murilo. Evaristo de Moraes Filho: pensador brasileiro. In: PESSANHA, Elina; VILLAS BÔAS, Glaucia: MOREL, Regina (Org.). Evaristo de Moraes Filho, um intelectual humanista. Rio de Janeiro: ABL, Topbooks, 2005.

CENTRO ACADÊMICO CANDIDO DE OLIVEIRA. CACO: 90 anos de história. Entrevista de Evaristo de Moraes Filho. Coordenadoria de Comunicação da Universidade Federal do Rio de Janeiro. Rio de Janeiro: UFRJ, 2007. Disponível em: <

http://www.ufrj.br/sgcoms/docs/Memorabilia-CACO-90-ANOS-de-HISTORIA.pdf $>$. Acesso em 10 jan. 2010.

FREITAS JÚNIOR, A. R. Direito do Trabalho na era do desemprego: instrumentos jurídicos em políticas públicas de fomento à ocupação. São Paulo: LTr, 1999.

FRENCH, John D. Afogados em leis: a CLT e a cultura política dos trabalhadores brasileiros. São Paulo: Fundação Perseu Abramo, 2001.

GOMES, Ângela de Castro. O problema do sindicato único no Brasil: um livro faz 50 anos. Locus: Revista de História. v. 9, n. 1, 2003. Disponível em: <http://locus.ufjf.emnuvens. com.br/locus/article/view/2468>. Acesso em 04 out. 2015.

; PESSANHA, Elina; MOREL, Regina. Arnaldo Sussekind, um construtor do direito do trabalho. Rio de Janeiro: Renovar, 2004.

2010. . Memória da Justiça do Trabalho: trajetória de juízes. Porto Alegre: POA,

; SILVA, Fernando Teixeira da (Org.). A Justiça do Trabalho e sua história.

Campinas: Ed. Unicamp, 2013.

MENDONÇA, Joseli Maria Nunes. Evaristo de Moraes: tribuno da República. São Paulo: Editora da Unicamp, 2007. 
MORAES, Evaristo de. Apontamentos de direito operário. $3^{\text {a }}$ ed.. São Paulo: LTr, 1986.

MORAES FILHO, Evaristo. Introdução ao Direito do Trabalho. Rio de Janeiro: Revista Forense, 1956, v. I e II.

Anteprojeto de Código do Trabalho. Rio de Janeiro: Departamento de Imprensa Nacional, 1963.

. Tratado Elementar de Direito do Trabalho. $2^{\text {a }}$ ed. Rio de Janeiro: Livraria Freitas Bastos, 1965, v. I.

Temas atuais de trabalho e previdência. São Paulo: LTr, 1975.

. O problema do Sindicato Único no Brasil: seus fundamentos sociológicos. $2^{\mathrm{a}}$ ed. São Paulo: Alfa-ômega, 1978.

Introdução. In: MORAES Evaristo de. Apontamentos de direito operário. $3^{\mathrm{a}}$ ed. São Paulo: LTr, 1986.

LTr, 1993.

Do contrato de trabalho como elemento da empresa. Ed. fac-similar. São Paulo:

Renovar, 1997.

O problema de uma Sociologia do Direito. Ed. fac-similar. Rio de Janeiro,

MOREL, Regina; GOMES, Ângela Castro; PESSANHA, Elina (Org.). Sem medo da Utopia: Evaristo de Moraes Filho: arquiteto da sociologia e do direito do trabalho no Brasil. São Paulo: LTr, 2007.

Evaristo de Moraes Filho: produto e produtor da universidade. Revista Sociologia \& Antropologia. Rio de Janeiro, v.05.01, p. 299-314, abril de 2015, Disponível em:

$<$ http://revistappgsa.ifcs.ufrj.br/wp-content/uploads/2015/05/5-12_regina-

_lucia_moraes_morel.pdf $>$. Acesso em: 10 out. 2015.

OLIVEIRA, Luciano. Não fale do Código de Hamurabi! A pesquisa sócio jurídica na pósgraduação em Direito. Disponível em: < http://www.uniceub.br/media/180293/Texto_IX. pdf>. Acesso em: 14 jan. 2015.

PALOMEQUE, Manuel-Carlos. Direito do Trabalho e Ideologia. Coimbra: Almedina, 2001.

PESSANHA, Elina; VILLAS BOAS, Glaucia: MOREL, Regina (Org.). Evaristo de Moraes Filho, um intelectual humanista. Rio de Janeiro: ABL, Topbooks, 2005.

Evaristo de Moraes Filho: fundamentos democráticos dos direitos do trabalho no Brasil. In: PESSANHA, Elina; VILLAS BÔAS, Glaucia: MOREL, Regina (Org.). Evaristo de Moraes Filho, um intelectual humanista. Rio de Janeiro: ABL, Topbooks, 2005. 
PINHEIRO, Paulo Sérgio. Prefácio à $2^{a}$ Edição. In: Evaristo de Moraes Filho. O Problema do Sindicato Único no Brasil: seus fundamentos sociológicos. $2^{\text {a }}$ ed. São Paulo: AlfaÔmega, 1978.

VENÂNCIO FILHO, Alberto. O pensamento social de Evaristo de Moraes Filho. In: PESSANHA, Elina; VILLAS BÔAS, Glaucia: MOREL, Regina (Org.). Evaristo de Moraes Filho, um intelectual humanista. Rio de Janeiro, ABL, Topbooks, 2005, p. 21-40.

VILLAS BÔAS, Glaucia. O insolidarismo revisitado em O problema do Sindicato Único no Brasil. In: PESSANHA, Elina; VILLAS BOAS, Glaucia: MOREL, Regina (Org.). Evaristo de Moraes Filho, um intelectual humanista. Rio de Janeiro, ABL, Topbooks, 2005.

VILLAS BÔAS, Glaucia. Evaristo de Moraes Filho e a maioridade dos trabalhadores brasileiros. Revista Brasileira de Ciências Sociais. São Paulo, v. 19, n. 55, p. 19-32, jun. 2004. Disponível em: <http://www.scielo.br/scielo.php?script=sci_arttext\&pid=S010269092004000200002\&lng=pt\&nrm=iso >. Acesso em: 12 out. 2015. 